\title{
HONGOS AISLADOS DESDE SUELOS CONTAMINADOS CON PETROLEO
}

\author{
(Fungi isolated from petroleum-polluted soil)
}

\author{
Eduardo Valenzuela $\mathbf{F}^{\mathbf{1}}$., Loretto Solís $\mathbf{M}^{\mathbf{1}}$., \\ Oscar Martínez $\mathbf{V}^{\mathbf{1}}$. \& Dante Pinochet $\mathrm{T}^{2}$. \\ ${ }^{1}$ Instituto de Microbiología. Facultad de Ciencias, Universidad \\ Austral de Chile. Casilla 167, Valdivia - Chile. \\ ${ }^{2}$ Instituto de Ingeniería Agraria y Suelos. Facultad de Agronomía, \\ Universidad Austral de Chile. Casilla 567, Valdivia - Chile.
}

Palabras claves: Hongos, suelo, petróleo, biodegradación,Chile.

Key word: Fungi, soil, petroleum, biodegradation, Chile.

\section{RESUMEN}

Desde suelos de la XII Región de Chile contaminados y no contaminados con petróleo crudo, se aislaron un total de 240 cepas fúngicas agrupadas en 15 géneros y un micelio estéril, que mayoritariamente correspondieron a los géneros Penicillium (130), Absidia (32) y Mortierella (29). Por su capacidad de crecimiento y mayor peso seco micelial en agar y caldo mineral adicionado de petróleo crudo al 1\%, se seleccionaron las cepas Dd202, Dd219 de Mortierella spp. y Dd225 de Penicillium sp., para determinar su cinética degradativa a lo largo del tiempo ( 9,18 y 36 días). Utilizando espectrofotometría infrarroja se determinaron las fracciones del petróleo que fueron degradadas por las 3 cepas, que correspondieron a fracciones cuyas frecuencias se encuentran entre 2850 y $1800 \mathrm{~cm}^{-1}$ (aldehídos, alquinos y anhídridos) y entre 1510 y $1000 \mathrm{~cm}^{-1}$ (alcanos saturados e insaturados, aromáticos y alquilos).

\section{INTRODUCCION}

En Chile el 19 de junio de 1950, se promulgó la Ley 9.618 que creó la Empresa Nacional del Petróleo (ENAP). En las décadas siguientes, se construyeron oleoductos y nuevos terminales para recibir la producción de petróleo proveniente de Magallanes. En el plano internacional, la empresa se adhiere a la normativa emanada de tratados y acuerdos internacionales de carácter ambiental y sanitario para la calidad y manipulación de combustibles, preocupándose también por minimizar el riesgo de accidentes ecológicos en el transporte de sus productos. En este aspecto, destacan el Convenio Internacional firmado en 1954, relativo a la

\section{ABSTRACT}

A total of 240 fungal strains grouped in 15 genera and a sterile mycelium which corresponded mostly to genera Penicillium (130), Absidia (32) and Mortierella (29) were isolated from soils of the XII Region of Chile that had been polluted or not with raw petroleum. Strains Dd202, Dd219 of Mortierella spp. and Dd225 of PeniciIlium sp. were selected because of their ability of growth and major mycelial dry weight in agar and mineral broth added with $1 \%$ raw petroleum in order to determine their degradative kinetics with time (9,18 and 36 day). By means of infrared spectrophotometry, fractions of petroleum that had been degraded by the three strains could be established, the frequencies of which being between 2850 and $1800 \mathrm{~cm}^{-1}$ (aldehyde,alkine and anhydride) and between 1510 and $1000 \mathrm{~cm}^{-1}$ (saturated and insaturated alkane, aromatic and alkyle)

intervención en alta mar en casos de accidentes por contaminación por hidrocarburos (Empresa Nacional del Petróleo, 2004). Los análisis de petróleo crudo magallánico solicitados por ENAP a empresas particulares, indican que las características son: bajo en contenido de azufre (dulce) y de acuerdo a su densidad API es ligero o súper ligero, parafínico de cadena larga (Alcanos). En los últimos años, en algunos suelos de Magallanes cercanos a los sitios de acopio de petróleo, poliductos, procesamiento del petróleo, etc., se han determinado distintos niveles de contaminación por este agente crudo o algunos de sus derivados. Las áreas contaminadas por parte de ENAP, no presentan registros detallados del tipo de suelo contaminado, tipo de hidrocarburos del petróleo o fecha del derrame. ENAP consciente de la alteración de estos suelos y de acuerdo a las norma- 
tivas medioambientales imperantes en nuestro país, se ha hecho eco y deber de recuperar estos suelos para uso agrícola o forestal. Una posible solución para recuperarlos es mediante una biorremediación, haciendo uso de aquellos microorganismos (hongos o bacterias) que viven en ellos.

Las bacterias son menos efectivas que los hongos en la degradación de hidrocarburos, pues estos últimos poseen una batería enzimática más eficientes (Munnecke \& Huysmans, 1998). Autores como Bouchez et al. (1996), Yateem et al. (1998) y Juhasz \& Naidu (2000), presentan listas de bacterias y hongos que son capaces de degradar amplios espectros de contaminantes del petróleo, estos microorganismos proceden de ambientes marinos, pozos y suelos. Lemos et al. (2002), indican que las especies de hongos de los géneros Thichoderma y Mortierella son las más comúnmente aisladas desde suelos contaminados con este hidrocarburo y las pertenecientes a los géneros Aspergillus y Penicillium se aíslan con mayor frecuencia desde ambientes marinos y terrestres con este contaminante; estos mismos autores indican que en Brasil , se aislaron especies fúngicas como Aspergillus niveus, $\boldsymbol{A}$. niger, $A$. versicolor, $A$. terreus, A. fumigatus, Penicillium corylophilum, Paecilomyces variotii, P. niveus y Fusarium sp. Además se determinó que A. versicolor presenta una alta eficiencia de biodegradación del petróleo (10.8\%), estos resultados coinciden con los obtenidos en otras zonas petroleras. Por su parte, April et al. (2000), identificaron varias especies de los géneros Trichoderma, Penicillium, Aspergillus y Gliocladium en este substrato en Canadá. Okerentugba \& Ezeronye (2003), aislaron Penicillium, Aspergillus y Rhizopus desde aguas contaminadas con petróleo donde se observó su capacidad degradativa. Estos microorganismos posiblemente son oxidadores de hidrocarburos y deben poseer en la membrana citoplasmática un grupo específico de oxigenasas (Rosenberg \& Ron, 1998). Abu-Elgheit \& Yusef (1980), determinaron mediante espectrofotometría infrarroja, que cepas de Penicillium aisladas desde áreas expuestas a filtraciones de petróleo, al octavo día de tratamiento tenían la capacidad de degradar hidrocarburos parafínicos y aromáticos.

Químicamente, el petróleo está formado por una mezcla compleja de hidrocarburos que se clasifican en 4 tipos: saturados (alcanos y cicloalcanos), aromáticos, asfáltenos (fenoles, ácidos grasos, cetonas, ésteres y porfirinas) y resinas (piridinas, quinolines, carbazoles, sulfóxidos y amidas) (Colwell \& Walker, 1977; Madigan et al., 1999).

Debido a la naturaleza compleja de los compuestos del petróleo, la mayoría de los microorganismos del suelo no pueden crecer en su presencia, aunque existe una tolerancia microbiana, esto induce a la selectividad y disminución de la biodiversidad (Atlas et al., 1991). Existe una diferencia al degradar los hidrocarburos, donde los compuestos saturados y aromáticos con 1 y 5 anillos bencénicos son utilizados como fuente energética, en cambio, los aromáticos de alto peso molecular (resinas y asfáltenos) son difíciles de degradar por su recalcitrancia (Sugiura et al., 1997).

La liberación de petróleo a medios acuáticos y terrestres, sea por procesos naturales o por la actividad humana, provocan alteraciones en estos ecosistemas, pues existen una serie de limitantes como las bajas temperaturas, escasez de nutrientes minerales (N, P) y la falta de oxígeno entre otras para su biodegradación (Atlas, 1981; Madigan et al., 1999). Hou et al. (1999), señalan que los suelos contaminados con petróleo son clasificados peligrosos para microorganismos y plantas.

En base a lo expuesto se planteó aislar hongos desde suelos de la XII Región de Chile contaminados con petróleo crudo y determinar su capacidad para degradar en condiciones de laboratorio algunas fracciones de los hidrocarburos que lo conforman.

\section{MATERIALES Y METODOS}

1. Recolección de muestras de suelo: la zona en estudio corresponde a las instalaciones de la Empresa Nacional del Petróleo (ENAP) en la XII Región de Chile, en los sectores denominados:1.- Posesión (0517136 E y 4204645 N) ubicado en la comuna de San Gregorio, Punta Arenas, 2.- Catalina sur (0523808 E y 4153522 N) ubicado en la comuna de Primavera, sector oriental de la Isla de Tierra del Fuego y 3.- Clarencia (0440236 E y 4144195 N) comuna de Primavera en la Isla de Tierra del Fuego.

Se recolectaron muestras de suelos no contaminados y contaminados, debido a derrames por la ruptura de calentadores situados cada cierto tramo de los ductos. En cada sector de muestreo (no contaminado y contaminado) se delimitó una parcela de 5 x $5 \mathrm{~m}$ y con una pala estéril a dos profundidades (0-20 y 20-40 cm) se recolectaron independientemente 3 muestras de $500 \mathrm{~g}$ de suelo de cada profundidad . Cada muestra fue depositada independientemente en bolsas y transportada al Instituto de Microbiología de la Facultad de Ciencias, Universidad Austral de Chile.

2. Procesamiento de muestras de suelos, aislamientos de cepas fúngicas y su identificación. Las tres muestras de suelo del mismo sector y profundidad se mezclaron para obtener una muestra compuesta y representativa; de ella se pesaron $10 \mathrm{~g}$, se depositaron en un matraz que contenía $100 \mathrm{~mL}$ de agua destilada estéril, luego en un agitador orbital se agitó la mezcla por 10 min a 1500 r.p.m. A continuación se realizaron diluciones seriadas (hasta $10^{-6}$ ) en tubos que contenían $9 \mathrm{~mL}$ de agua destilada estéril. 
Para el aislamiento de los hongos, cada dilución fue sembrada independientemente y por triplicado, en placas de Petri estériles donde se depositó $1 \mathrm{~mL}$ de la dilución respectiva, $0.5 \mathrm{~mL}$ de mezcla de antibióticos $(50 \mu \mathrm{g} / \mathrm{mL}$ de penicilina y $25 \mu \mathrm{g} / \mathrm{mL}$ de estreptomicina) y $10 \mathrm{~mL}$ de agar malta al $2 \%$ (AEM) fundido y a $45^{\circ} \mathrm{C}$; luego la mezcla se homogenizó y una vez solidificado el agar las placas se incubaron a $23 \pm 2^{\circ} \mathrm{C}$ por 10 días. Las colonias obtenidas fueron repicadas en tubos que contenían AEM inclinado y se incubaron a $23^{\circ} \mathrm{C}$ por 10 días. Del total de colonias obtenidas, se seleccionaron 20 cepas fúngicas, de cada suelo (no contaminados y contaminados) y profundidad (0-20 y 20-40 cm), utilizando principalmente como criterio el color de las colonias. Para la identificación taxonómica de las cepas, se realizó una caracterización macroscópica de las colonias en AEM, agar papa dextrosa y agar Czapeck a los 7 días de incubación a $23 \pm 2{ }^{\circ} \mathrm{C}$. También se realizó un examen microscópico del micelio mediante preparaciones en fresco y como líquido de montaje se usó agua y lactofenol. Los datos macro-microscópicos obtenidos se confrontaron con los que aparecen en las claves taxonómicas de Von Arx (1981) textos y monografías micológicas, como Domsch, et al. (1980), Ainsworth \& Bisby’S (1995), Ramírez (1982), Botth (1977) y Ellis (1976).

3. Selección de cepas fúngicas en medio mineral adicionado de petróleo: desde el cultivo fresco de las cepas en estudio, se extrajo con un sacabocado de $15 \mathrm{~mm}$ de diám., un círculo de agar con micelio y se depositó en el centro de una placa que contenía $\mathrm{AMI}+\mathrm{P}$ (agar mineral inorgánico: $0,1 \mathrm{~g} \mathrm{CaCl}_{2}$; $0,5 \mathrm{~g} \mathrm{KCl} ; 1 \mathrm{~g} \mathrm{KH}_{2} \mathrm{PO}_{4} ; 0,5 \mathrm{~g}$ $\left(\mathrm{NH}_{4}\right)_{2} \mathrm{SO}_{4} ; 0,2 \mathrm{~g} \mathrm{MgSO}_{4} ; 7 \mathrm{H}_{2} \mathrm{O} ; 10 \mathrm{~g}$ agar-agar, $\mathrm{H}_{2} \mathrm{O}$ destilada $1000 \mathrm{~mL}, \mathrm{pH}$ 6,2) adicionado de petróleo crudo ( $1 \% \mathrm{vol} / \mathrm{vol}$ ), paralelamente se sembró otro círculo de agar con micelio en una placa que contenía AEM al 2\% (medio de control). Las placas sembradas se incubaron a $23 \pm 2$ ${ }^{0} \mathrm{C}$ por 20 días, período en que se realizó la evaluación. Para seleccionar las potenciales cepas que utilizaron el petróleo (24 en total, dos cepas de cada suelo y de cada profundidad) se empleó como criterio el diámetro alcanzado por la colonia y el peso seco micelial (PSM) originado a los 20 días de incubación en AM+P.

Para determinar el PSM desde la placa que contenía la cepa fúngica: se extrajo el micelio, se secó a $60{ }^{\circ} \mathrm{C}$ en una estufa hasta peso constante y luego del peso obtenido, se restó el peso seco de un círculo de agar con el micelio respectivo.

\section{Cultivo de cepas fúngicas en caldo mineral inorgá- nico más petróleo.}

Cada una de las cepas preseleccionadas (24 cepas) fueron sembradas en forma individual y por duplicado en matraces que contenían $100 \mathrm{~mL}$ de CMI+P (caldo mineral inorgánico, cuyos constituyentes son los mismos indicados para el medio AMI+P pero sin agar-agar) adicionado con petróleo crudo al $1 \%$, al interior del matraz se depositaron 3 círculos de agar con micelio de $15 \mathrm{~mm}$ de diám., obtenidos desde un cultivo fresco de la cepa en estudio. Sembrados los matraces se incubaron a $23 \pm 2{ }^{\circ} \mathrm{C}, 150$ r.p.m por 18 días en un agitador orbital. Al término del período de incubación, el contenido de cada matraz fue filtrado a través de filtros de papel Whatman 2. El micelio del hongo retenido en los filtros fue secado a $60^{\circ} \mathrm{C}$ y luego se determinó el PSM (como se indicó en el punto 3). De las 24 cepas ensayadas se seleccionaron 3 (independiente del tipo de suelo y profundidad analizada), las que presentaron los mayores PSM se utilizaron para una cinética degradativa de petróleo crudo.

\section{Cinética degradativa de petróleo crudo y determi- nación de fracciones de petróleo.}

Para determinar la mejor cepa fúngica capaz de degradar algunos de los constituyentes del petróleo crudo se realizó una cinética degradativa de petróleo a lo largo del tiempo. Cada una de las cepas seleccionadas se trató individualmente por duplicado y aproximadamente unos 50.000 propágulo se sembraron en matraces que contenían $200 \mathrm{~mL}$ de CMI+P más $2 \%$ de petróleo crudo y se incubaron a $23 \pm 2{ }^{\circ} \mathrm{C}$ y 150 r.p.m en un agitador orbital. A los 9, 18 y 36 días, se retiraron los matraces del agitador y el contenido se filtró a través de papel Whatman 2. Para determinar las fracciones del petróleo degradadas, los filtrados fueron enviados a la Empresa Nacional de Petróleo (ENAP), ubicada en la ciudad de Punta Arenas, donde técnicos utilizando protocolos estándar establecieron las fracciones de hidrocarburos degradadas mediante espectrofotometría infrarroja.

\section{RESULTADOS Y DISCUSION}

La mayor variedad de taxa (7) se determinó en el suelo Catalina sur (20-40 cm de profundidad) y a excepción de la muestra de suelo Clarencia $(0-20 \mathrm{~cm}$ de profundidad), en todas las demás predominaron las cepas pertenecientes al género Penicillium y una menor predominancia la presentaron cepas de los géneros Beauveria, Cunninghamella, Mucor, Pithomyces y Ulocladium (Tabla 1). En estudios similares, Lemos et al. (2002), en suelos de Brasil (Guararema) contaminados accidentalmente con petróleo, aislaron hongos de los géneros Aspergillus, Penicillium, Paecilomyces, y Fusarium. Radwan et al. (1995), determinaron a nivel de la rizósfera de plantas de tomates contaminadas con petróleo, hongos de los géneros Penicillium y Fusarium. April et al. (2000), indican que desde pastos de suelos 
con este contaminante en el oriente y suroeste de Canadá, se aislaron en agar mineral adicionado de petróleo especies de los géneros Aspergillus, Penicillium, Gliocladium, Trichoderma y Ulocladium. Rivera-Cruz et al. (2002), aislaron de la rizósfera del pasto alemán (Echinochloa polystacha) en suelos con derrame reciente de petróleo y de pasto cabezón (Paspalum virgatum) con derrame constante, hongos pertenecientes a los géneros Trichoderma, Penicillium, Beauveria, Aspergillus, Mucor y Paecilomyces.

Los resultados del presente estudio coinciden con los de los autores anteriormente señalados, en la presencia de cepas pertenecientes a los géneros Aspergillus, Acremonium, Beauveria, Fusarium, Mortierella, Mucor y Penicillium. También, desde suelos no contaminados se aislaron cepas de hongos de los géneros Beauveria, Trichoderma y Mucor. Los integrantes de los géneros Cunninghamella y Wallemia, no aparecen citadas en la literatura consultada referente a este tipo de suelo.

A partir del crecimiento de las cepas fúngicas (240 en total) en agar mineral inorgánico adicionado de petróleo crudo al 1\% (AMI+ P), luego de 20 días de incubación, el tamaño de las colonias varió entre 0 a $7 \mathrm{~cm}$ de díam. y el PSM entre 0 y 0.42 g. En base a esto, se seleccionaron 24 cepas, con diam. entre 3.3 a $7 \mathrm{~cm}$ y un PSM entre 0.18 y 0.42 g. A los 18 días de cultivo en caldo mineral inorgánico adicionado con petróleo crudo al 1\% (CMI+P), registraron un PSM que varío entre 3.21 a $5.41 \mathrm{~g}$, de acuerdo a estos últimos resultados se seleccionaron 3 cepas para realizar la cinética degradativa de petróleo crudo. La primera cepa fue la Dd202 Mortierella sp., aislada de suelo no contaminado (20-40 cm de profundidad) del sector Clarencia con un PMS de 5.16 g. La segunda cepa corresponde a la Dd219 Mortierella sp., aislada de suelo contaminado (20$40 \mathrm{~cm}$ de profundidad) con petróleo del sector Clarencia con un PMS de 4.98 g. La tercera cepa fue la Dd225 Penicillium sp., aislada de suelo no contaminado (20-40 cm de profundidad) del sector Clarencia con un PMS de $5.41 \mathrm{~g}$.

Rivera-Cruz et al. (2002), ensayaron el crecimiento de 46 hongos en un medio de cultivo sólido enriquecido con petróleo al 1\%; estos autores señalan que 20 hongos de los 46 ensayados (42\%), crecieron en el sustrato utilizado y 15 hongos de los 46 cultivados en medio líquido con petróleo al 1\%. Estos resultados concuerdan con los del presente estudio pues de las 240 cepas ensayadas en $\mathrm{AMI}+\mathrm{P}$, solo 4 cepas fúngicas no crecieron y en el ensayo en CMI adicionado de petróleo crecieron todas la cepas (24) en estudio.

Madigan et al. (1999), señalan que el petróleo es una rica fuente de materia orgánica, y los hidrocarburos que contienen son fácilmente utilizados por diferentes microorganismos en condiciones aeróbicas. En cuanto a los hongos que en el presente estudio no crecieron en el medio AMI+P, esto podría atribuirse a la falta de las enzimas necesarias para degradar los constituyentes del

Tabla 1. Taxa fúngicos aislados desde dos profundidades $(0-20$ y 20-40 cm) de suelos contaminados y no contaminados con petróleo de tres sectores de la XII Región de Chile.

\begin{tabular}{|c|c|c|c|c|c|c|c|c|c|c|c|c|c|}
\hline \multirow{3}{*}{ TAXA } & \multicolumn{4}{|c|}{ Suelo Catalina Sur } & \multicolumn{4}{|c|}{ Suelo Clarencia } & \multicolumn{4}{|c|}{ Suelo Posesión } & \multirow[b]{2}{*}{ Total } \\
\hline & A & A & B & B & A & A & B & B & A & A & B & B & \\
\hline & $0-20 \mathrm{~cm}$ & $20-40 \mathrm{~cm}$ & $0-20 \mathrm{~cm}$ & $20-40 \mathrm{~cm}$ & $0-20 \mathrm{~cm}$ & $20-40 \mathrm{~cm}$ & $0-20 \mathrm{~cm}$ & $20-40 \mathrm{~cm}$ & $0-20 \mathrm{~cm}$ & $20-40 \mathrm{~cm}$ & $0-20 \mathrm{~cm}$ & $20-40 \mathrm{~cm}$ & Cepas \\
\hline Absidia sp. & - & - & - & - & 3 & 2 & 15 & 5 & 2 & 4 & - & 1 & 32 \\
\hline Acremonium sp. & 1 & 1 & 2 & - & - & - & 1 & 1 & - & - & - & - & 6 \\
\hline Aspergillus niger & - & - & 2 & 3 & 1 & 1 & 1 & - & - & - & 1 & 1 & 10 \\
\hline Beauveria sp. & & 1 & - & - & - & - & - & - & - & - & - & - & 1 \\
\hline Cladosporium sp. & - & - & - & 2 & - & - & - & - & - & 1 & - & - & 3 \\
\hline Cunninghamella sp. & - & - & 1 & - & - & - & - & - & - & - & - & - & 1 \\
\hline Fusarium sp. & - & 1 & - & - & - & 1 & - & 3 & - & - & - & - & 5 \\
\hline Mortierella sp. & 5 & 7 & - & 4 & 1 & - & - & 4 & 1 & 5 & 2 & - & 29 \\
\hline Mucor sp. & - & - & - & - & - & - & - & 1 & - & - & - & - & 1 \\
\hline Penicillium sp. & 11 & 8 & 9 & 8 & 15 & 13 & 3 & 6 & 15 & 10 & 15 & 17 & 130 \\
\hline Phoma sp. & - & - & 1 & - & - & 1 & - & - & 2 & - & - & 1 & 5 \\
\hline Pithomyces sp. & - & 1 & - & - & - & - & - & - & - & - & - & - & 1 \\
\hline Trichoderma sp. & 2 & 1 & - & - & - & 1 & - & - & - & - & - & - & 4 \\
\hline Ulocladium sp. & - & - & - & - & - & - & - & - & - & - & 1 & - & 1 \\
\hline Wallemia sebi & - & - & 4 & 3 & - & - & - & - & - & - & - & - & 7 \\
\hline Micelio estéril & - & - & - & - & - & - & - & - & - & - & 1 & - & 1 \\
\hline No determinadas & 1 & - & 1 & - & - & 1 & - & - & - & - & - & - & 3 \\
\hline TOTAL & 20 & 20 & 20 & 20 & 20 & 20 & 20 & 20 & 20 & 20 & 20 & 20 & 240 \\
\hline
\end{tabular}

A = suelo no contaminado con petróleo. $\mathrm{B}$ = suelo contaminado con petróleo 
petróleo. Por su parte, Baldrían \& Gabriel (1997) y Mandal et al. (1998), señalan que los hidrocarburos aromáticos policíclicos (PAHs) a menudo están acompañados de la presencia de altas cantidades de metales pesados como cadmio, cobre o mercurio, tóxicos para los hongos que producen pudrición blanda y para la microbiota del suelo.

Los espectros de absorbancia del petróleo crudo tratado con la cepa Dd202 y las fracciones remanentes resultantes, se muestran en la Fig. 1 , observándose que al día 9 de tratamiento, producto de la degradación de algunas fracciones del petróleo se generaron otros constituyentes, cuyos picos de absorbancia ( $\mathrm{A}^{\circ}$ ) más característicos fueron en las frecuencias de $2800 \mathrm{~cm}^{-1}$ (aldehídos); $1990 \mathrm{~cm}^{-1}$ y $1950 \mathrm{~cm}^{-1}$ (aromáticos) y $750 \mathrm{~cm}^{-1}$ que corresponden a enlaces C-Cl. Para el día 18, se observa que siguen disminuyendo las fracciones del petróleo crudo y se forman nuevos picos de $\mathrm{A}^{\mathrm{o}}$, que se registran a los 1250 $\mathrm{cm}^{-1}$ correspondientes a anhídridos y en la frecuencia $1050 \mathrm{~cm}^{-1}$ que corresponden a enlaces C-O, C-N y C-Cl. Al día 36 la degradación sigue ocurriendo sin la formación de mayores constituyentes.

Al día 9 de incubación los espectros de absorbancia con la cepa Dd219 y las fracciones remanente resultantes, se observó que prácticamente todos sus componentes sufrieron una degradación parcial, siendo las fracciones más degradadas las correspondientes a las frecuencias entre $2800 \mathrm{~cm}^{-1}$ y $1800 \mathrm{~cm}^{-1}$ que corresponden a grupos aldehídos y compuestos nitrogenados, también las fracciones de hidrocarburos de las frecuencias desde $1500 \mathrm{~cm}^{-1}$ a $1000 \mathrm{~cm}^{-1}$ sufrieron degradación, estas corresponden a compuestos alcanos saturados (posibles compuestos pertenecientes a metano, etano, propano, butano) y otros como alcanos insaturados (que podrían pertenecer a los grupos etileno, propileno y 1-buteno), alquilos, compuestos nitrogenados y otros compuestos con enlaces C-O, C-N y C-Cl. Por el contrario, las fracciones que fueron degradadas en menor proporción, corresponden a las frecuencias entre $3700 \mathrm{~cm}^{-1}$ y $2850 \mathrm{~cm}^{-1}$ (pertenecientes a los grupos aminas, alcoholes, alcanos saturados e insaturados, alquilos y fenoles), las frecuencias desde $1750 \mathrm{~cm}^{-1} \mathrm{a} 1560 \mathrm{~cm}^{-1}$ (correspondientes a los grupos amidas, alcanos insaturados, aldehídos, cetonas y ésteres) y las frecuencias desde $800 \mathrm{~cm}^{-1}$ a $500 \mathrm{~cm}^{-1}$ pertenecientes a

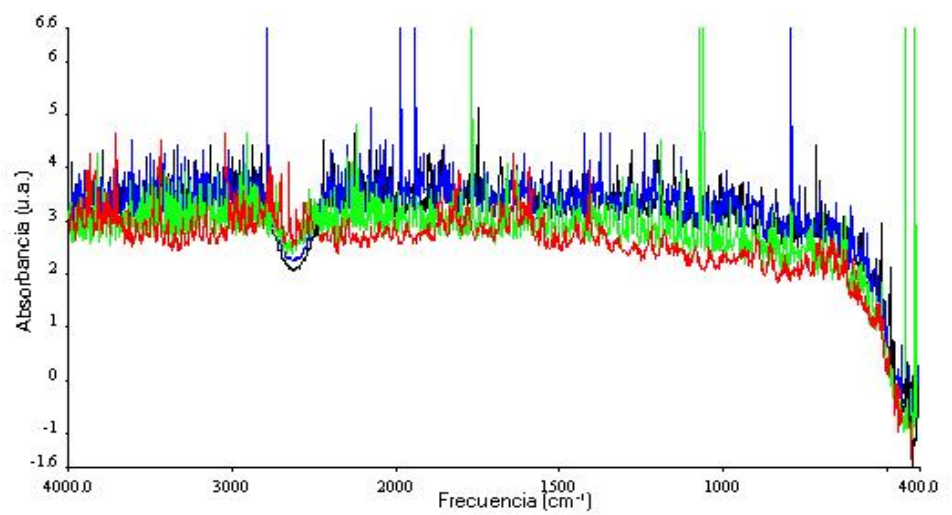

Figura 1. Espectro infrarrojo de petróleo crudo degradados por la cepa Dd202 Mortierella sp., en caldo mineral inorgánico. Espectros del petróleo crudo ( • ) y de las fracciones remanentes del petróleo a los días 9 ( e ) 18 ( e ) y 36 ( e ).

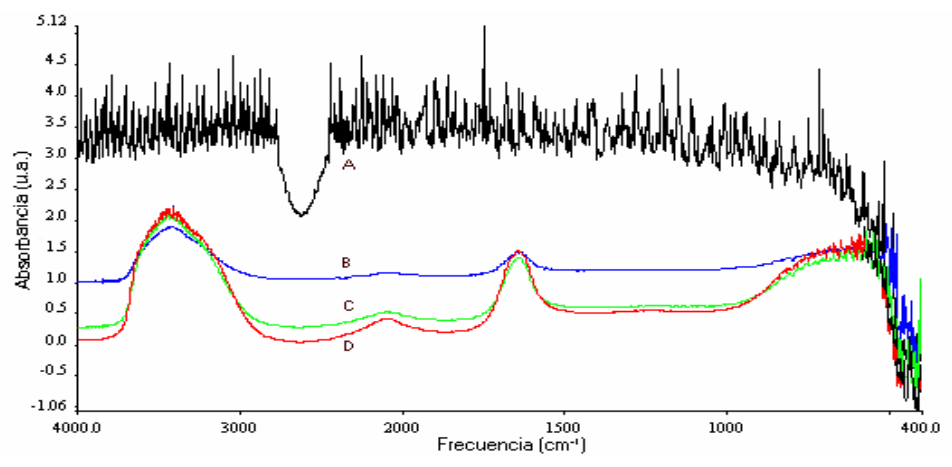

Figura 2. Espectro infrarrojo de petróleo crudo degradado por la cepa Dd219 Mortierella sp., en caldo mineral inorgánico. (A) = Espectro de absorbancia de petróleo crudo. $(B)=$ fracciones remanentes del petróleo a los 9 días. $(\mathrm{C})=18$ fracciones remanentes del petróleo a los 18 días. $(\mathrm{D})$ = fracciones remanentes del petróleo a los 36 días.

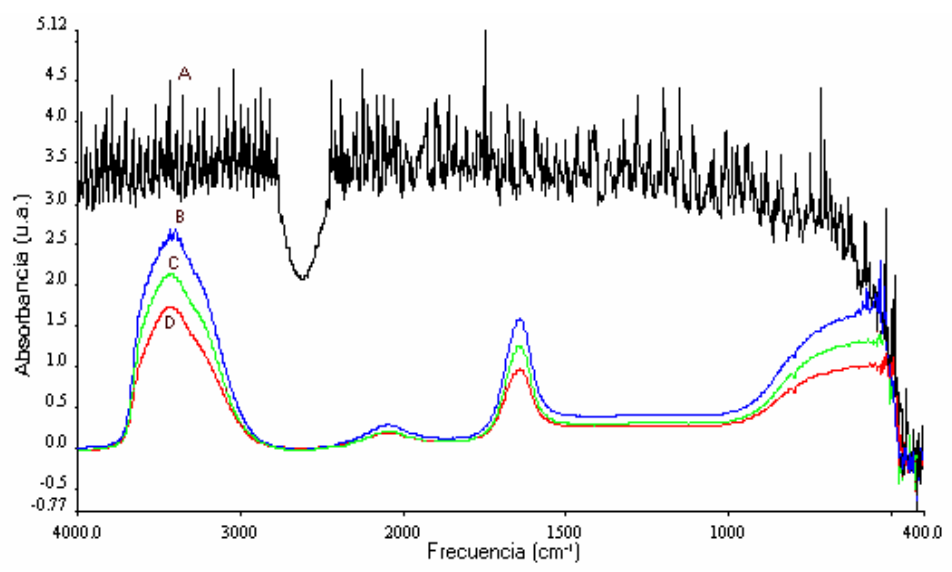

Figura 3. Espectro infrarrojo de petróleo crudo degradado por la cepa Dd225 Penicillium sp., en caldo mineral inorgánico. (A) = Espectro de absorbancia del petróleo crudo. $(B)$ = fracciones remanentes del petróleo a los 9 días. (C) = fracciones remanentes del petróleo a los18 días. (D) = fracciones remanentes del petróleo a los 36 días. 
arilo disulfuro (S-S), y disulfuro (C-S y S-S). Al día 18 y 36, se registró la misma tendencia observada al día 9 de incubación, tanto para las fracciones más y menos degradadas del petróleo crudo (Figura 2).

Al día 9 de incubación, los espectros de absorbancia con la cepa Dd225 y las fracciones remanentes resultantes mostraron una degradación total de los constituyentes de las frecuencias entre $2800 \mathrm{~cm}^{-1}$ y 2400 $\mathrm{cm}^{-1}$ (que corresponden a grupos aldehídos). También se observó una degradación parcial de prácticamente todos los constituyentes del petróleo crudo, siendo las fracciones más degradadas las de las frecuencias entre $1900 \mathrm{~cm}^{-1} \mathrm{y}$ $1800 \mathrm{~cm}^{-1}$ (grupos anhídridos) y las fracciones de hidrocarburos de las frecuencias desde $1500 \mathrm{~cm}^{-1} \mathrm{a} 1000 \mathrm{~cm}^{-1}$ donde se encuentran los grupos alcanos saturados, alcanos insaturados, alquilos, compuestos nitrogenados y compuestos que presentan enlaces $\mathrm{C}-\mathrm{O}, \mathrm{C}-\mathrm{N}$ y C-Cl. Al contrario, las fracciones degradadas en menor proporción corresponden a las frecuencias entre $3700 \mathrm{~cm}^{-1}$ y 2850 $\mathrm{cm}^{-1}$ (grupos aminas, alcoholes, alcanos saturados e insaturados, alquilos y fenoles), $2300 \mathrm{~cm}^{-1}$ a $1950 \mathrm{~cm}^{-1}$ (grupos alquinos y compuestos nitrogenados), $1750 \mathrm{~cm}^{-1}$ y 1560 $\mathrm{cm}^{-1}$ (grupos aldehídos, cetonas y esteres) y las fracciones correspondientes a las frecuencias desde $800 \mathrm{~cm}^{-1}$ a 500 $\mathrm{cm}^{-1}$, pertenecientes a arilo disulfuro (S-S), y disulfuro (C-S y S-S). A los días 18 y 36 de la cinética las $\mathrm{A}^{\circ}$ de las fracciones menos degradadas continúan disminuyendo en menor proporción (Figura 3).

De acuerdo a los resultados expuestos independiente del período de incubación (9, 18, y 36 días), la cepa Dd225 de Penicillium sp., es la que degrada una mayor variedad de los constituyentes del petróleo y a la inversa la cepa Dd202 de Mortierella sp. la menor variedad.

Según Colwell \& Walker (1977), los hidrocarburos del petróleo están constituidos principalmente por grupos saturados, aromáticos, asfaltenos y resinas. De los compuestos señalados, Pineda-Flores \& Mesta-Howard (2001), indican que los asfáltenos son uno de los más difíciles de degradar por su estructura molecular extremadamente compleja, los cuales presentan distintas proporciones de N, S y O, siendo su tiempo de eliminación desde una semana para las estructuras más simples, hasta 990 días para aquellos con varios anillos aromáticos condensados. Lo que concuerda con las fracciones de las cetonas, fenoles y amidas degradadas en menor proporción por las tres cepas fúngicas ensayadas a través del tiempo.

Abu-Elgheit \& Yusef (1980), en un estudio de degradación de petróleo con cepas de Penicillium aisladas desde áreas expuestas a su contaminación en las costas del mediterráneo, determinaron que al octavo día de tratamiento las cepas habían degradado hidrocarburos parafínicos y aromáticos. Oudot et al. (1993), observaron que Penicillium janthinellum tiene la capacidad de degradar fracciones de alifáticos y aromáticos, catabolizando parcialmente fracciones de resinas del petróleo crudo. Launen et al. (1995) y Kiehlmann et al. (1996), reportaron que $\boldsymbol{P}$. janthinellum, $\boldsymbol{P}$. pinophilum y $\boldsymbol{P}$. thomii, podrían transformar pireno y benzo[a]pireno a fenoles, dioles y quinonas. Esto concuerda con los resultados obtenidos para la cepa de Penicillium Dd225, que al noveno día de la cinética, degradó fracciones de hidrocarburos, compuestos aromáticos, aminos y alquilos entre otros. Por otra parte, se determinó que las cepas Dd202 y Dd219 del género Mortierella, presentaron igual capacidad para degradar los constituyentes del petróleo que la cepa Dd225, sin embargo, en la literatura consultada no se encontraron antecedentes de especies de Mortierella que degraden fracciones específicas del petróleo crudo, aunque Alexander (1994), señala que la mayoría de éstas son humíferas y presentan una gran capacidad para degrardar los constituyentes aromáticos que forman parte del humus.

\section{CONCLUSION}

Desde muestras de suelos contaminados y no contaminados con petróleo de la XII Región de Chile, se seleccionaron 3 cepas fúngicas, capaces de crecer en agar inorgánico mineral adicionado de petróleo crudo. Las cepas seleccionadas, 2 de Mortierella y una de Penicillium sometidas a una cinética degradativa de petróleo en condiciones de laboratorio y a lo largo del tiempo (hasta 36 días), presentaron la capacidad de degradar algunos de sus constituyentes de acuerdo a los análisis de espectrofotometría infrarroja.

\section{AGRADECIMIENTOS}

A la Empresa Nacional del Petróleo (ENAP) por todas las facilidades prestadas para realizar el presente estudio. A la Red Latinoamericana sobre Diversidad, Ecología y uso de hongos microscópicos (XII. J. CYTED - REDEMIC) y a la Dirección de Investigación de la Universidad Austral de Chile, por su ayuda en la realización del presente trabajo.

\section{REFERENCIAS}

Abu-Elgheit, M \& Yusef, H. (1980). Isolation of hydrocarbondegrading microorganisms in mediterranean waters. Environment International. 4:417-420

Ainsworth \& Bisby‘S. (1995). Dictionary of the fungi. CABI, 8th edición.

Alexander, M. (1994). Introducción a la Microbiología del Suelo. Segunda edición. Reimp. Agt Editor, S.A. México, D. F. 
April, T.; Foght, J \& Currah, R. (2000). Hydrocarbon-degrading filamentous fungi isolated from flare pit soils in northern and western Canada. Can. J. Microbiol. 46:38-49

Atlas, R. (1981). Microbial degradation of petroleum hydrocarbon: An environmental perspective. Microbial. Rev. 45:180-20

Atlas, R.; Horowitz, A.; Krichevky, M \& Bej, K. (1991). Response of microbial population of environmental disturbance . Microbiol. Ecol. 22:249-256

Baldrían, P. \& Gabriel, J. (1997). Effect of heavy metals on the growth of selected wood-rotting basidiomycetes. Folia Microbiol. 42:521-523

Booth, C. (1977). Fusarium. Laboratory guide to the identification of the major species. Commonwealth Mycological Institute. Kew, Surrey.

Bouchez, M.; Blanchet, D.; Haeseler, F. \& Vandecasteele, J. (1996). Les hydrocarbures aromatiques polycycliques dans I' environnement. Revue de I’ Institut français du pétrole. 51:797-828

Colwell, R. \& Walker, J. (1977). Ecological aspects of microbial degradation of petroleum in the marine environment. Crit. Rev. Microbiol. 5:423-445

Domsch, K.; Gams, W. \& Anderson, T. (1980). Compendium of soil fungi. Academic press London. 859 p.

Ellis, M. (1976). More dematiaceous Hyphomycetes. CMI, Kew.

Empresa Nacional del Petróleo, ENAP. (2004). www.ENAP.cl

Hou, F.; Leung, D.; Milke, M. \& Macpherson, D. (1999). Improvement in ryegrass seed germination for diesel contaminated soils by PEG treatment technology. Environmental Technology 20:413-418

Jushasz, A. \& Naidu, R. (2000). Bioremediation of high molecular weight polycyclic aromatic hydrocarbons: a review of the microbial degradation of benzo[a]pyrene. International Biodeterioration \& Biodegradation. 45:57-88

Kiehlmann, E.; Pinto, L. \& Moore, M. (1996). The bioremediation of chrysene to trans-1,2-dihydroxy-1,2-dihydrochrysene by filamentous fungi. Can. J. Microbiol. 42:604-608

Launen, L.; Pinto, L.; Wiebe, C.; Kiehlmann, E.; Moore, M. (1995). The oxidation of pyrene and benzo[a]pyrene by nonbasidiomycete soil fungi. Can. J. Microbiol. 41:477-488

Lemos, J.; Rizzo, C.; Millioli, V.; Soriano, U.; Sarquis, M.; Santos dos, R. (2002). Petroleum degradation by filamentous fungi. In: $9^{\text {th }}$ Annuual International Petroleum Conference, October 21-25, Novo México, EUA.
Madigan, M.; Martinko, J. \& Parker, J. (1999). Brock Biología de los microorganismos. Octava edición. Prentice may Iberia, Madrid. .

Mandal, T.; Baldrían, P.; Gabriel, J.; Nerud, F.; Zadrazil, F. (1998). Effect of mercury on the growth of wood-rotting basidiomycetes Pleurotus ostreatus, Pycnoporus cinnabarinus and Serpula lacrymans. Chemosphere 36:435-440

Munnecke, D. \& Huysmans, K. (1998). Fungal composting processes for polyaromatic hydrocarbons. Annual AAPG Conventions. Salt Lake City, Utah, USA. 5:17-20

Okerentugba, P. \& Ezeronye, O. (2003). Petroleum degrading potentials of single and mixed microbial cultures isolated from rivers and refinery effluent in Nigeria. African Journal of Biotechnology. 2:288292

Oudot, J.; Dupont, J.; Haloui, S. \& Roquebert, M. (1993). Biodegradation potential of hidrocarbon-degrading fungi in tropical soil. Soil Biol. Biochem. 25:1167-1173

Pineda-Flores, G. \& Mesta-Howard, A. (2001). Petroleum asphaltenes: generated problematic and possible biodegradation mechanisms. Revista Latinoamericana de Microbiología. 43:143-150

Radwan, S., Sorkoh, N \& El-Nemr, I. (1995). Oil biodegradation around roots. Nature. London. 376: 302.

Ramírez, C. (1982) Manual and atlas of the Penicillia. Elsevier Biochemical Press, Ámsterdam.

Rivera-Cruz, M., Ferrera-Cerrato, R., Volke H., Rodríguez, R \& Fernández, L. (2002). Adaptación y selección de microorganismos autóctonos en medios de cultivos enriquecidos con petróleo crudo. Terra 20:423-434.

Rosenberg, E. \& Ron, E. (1998). Bioremediation of petroleum contamination. In: R.L. Crawford Y D.L. Crawford edicion. Bioremediation: Principles and applications. Cambridge University Press. Cambridge, UK.

Sugiura, K.; Ishihara, M.; Shimauchi, T. \& Harayama, S. (1997). Physicochemical properties and biodegradability of crude oil. Environ. Sci. Technol. 31:45-51

Von Arx., J. (1981). The genera of fungi sporulating in pure culture. Tercera edición. J. Cramer, Germany.

Yateem, A.; Balba, M. \& Al-Wadhi, N. (1998). White rot fungi and their role in remediating oil-contaminated soil. Environment International 24:181-187 